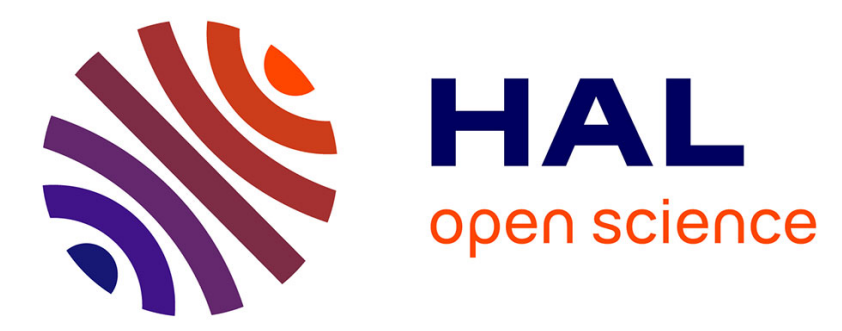

\title{
Is overweight still a problem of rich in sub-Saharan Africa? Insights based on female-oriented demographic and health surveys
}

Bertille Daran, Pierre Levasseur

\section{To cite this version:}

Bertille Daran, Pierre Levasseur. Is overweight still a problem of rich in sub-Saharan Africa? Insights based on female-oriented demographic and health surveys. World Development Perspectives, 2022, 25, 10.1016/j.wdp.2021.100388 . hal-03511042

\author{
HAL Id: hal-03511042 \\ https://hal.science/hal-03511042
}

Submitted on 17 Jan 2022

HAL is a multi-disciplinary open access archive for the deposit and dissemination of scientific research documents, whether they are published or not. The documents may come from teaching and research institutions in France or abroad, or from public or private research centers.
L'archive ouverte pluridisciplinaire HAL, est destinée au dépôt et à la diffusion de documents scientifiques de niveau recherche, publiés ou non, émanant des établissements d'enseignement et de recherche français ou étrangers, des laboratoires publics ou privés.

\section{(1) (1) $\$$}

Distributed under a Creative Commons Attribution - NonCommercial - NoDerivatives 44.0 
Title: Is overweight still a problem of rich in sub-Saharan Africa? Insights based on femaleoriented demographic and health surveys

Authors: Bertille Daran* and Pierre Levasseur**

Affiliations: *Sciences Po, Paris; **UMR SADAPT, INRAE, AgroParisTech, Univ. ParisSaclay

Email adresses: bertille.daran@sciencespo.fr; pierre.levasseur@inrae.fr

Corresponding author: Pierre Levasseur, UMR SADAPT AgroParisTech 16 rue Claude

Bernard 75231 Paris cedex 5, pierre.levasseur@inrae.fr

\begin{abstract}
To most people, sub-Saharan Africa (SSA) is synonymous with hunger and starvation. However, overweight and obesity are currently also a major public health concern in this region, sometimes even more than the prevalence of underweight. Despite the significant increase in the average body mass index (BMI) in SSA, the existing literature still considers a positive association between household socioeconomic status (SES) and individual BMI, suggesting that excess weight is a symbol of wealth while thinness is linked to poverty. This article aims to update this traditional and probably outdated perception by investigating potential nonlinearities and heterogeneity in the relationship between SES and BMI in SSA. First, we pool several cross-sectional female adult-oriented demographic and health surveys that are representative of a large number of SSA countries from 1990 to 2019. Second, we implement both ordinary least-squares (OLS) and instrumental variables (IV) regressions. Once a comprehensive set of observed characteristics was controlled for, OLS estimates suggest a nonlinear association between SES indicators and female BMI, taking a U-inverted shape. IV corrections controlling for reverse causality and unobserved heterogeneity reveal similar trends, confirming the overrepresentation of excess weight in intermediate levels of wealth and education. Furthermore, this study dates the social shift of the obesity burden in SSA: changing from positive to curvilinear from the end of the 1990s, including for countries currently classified as lower middle income. To conclude, this article contributes to the literature demonstrating the ongoing nutrition transition in SSA and the role of an emergent middle class in the rise of the obesity epidemic. This result has important implications for public health policies.
\end{abstract}

Key words: sub-Saharan Africa; overweight; obesity; socioeconomic status; middle class. 


\section{Introduction}

The prevalence of adult overweight and obesity nearly doubled between 1980 and 2014 to reach $39 \%$ and 13\%, respectively (World Health Organization, 2014). ${ }^{1}$ This major health concern was originally limited to high income countries but is now spreading to low and middle income countries, including in sub-Saharan Africa (SSA). Between 1975 and 2014, trends in the average men's body mass index (BMI) increased by around $1.5 \mathrm{~kg} / \mathrm{m}^{2}$ per decade in several SSA countries (NCD Risk Factor Collaboration, 2016). The obesity issue is even more alarming among African women for who the prevalence is twice that among men (World Health Organization, 2014). ${ }^{2}$ Likewise, the prevalence of early childhood overweight (adjusted for age and gender) almost doubled between 2000 and 2013 in Southern African countries, increasing from $11 \%$ to $19 \%$ (World Health Organization, 2014).

Concomitantly, the prevalence of underweight remained relatively high in the poorest regions of SSA (NCD Risk Factor Collaboration, 2016). The literature discusses the double burden of malnutrition by referring to the coexistence of hunger and obesity in most of SSA countries (Shekar \& Popkin, 2020). This double burden makes public health issues notably more complex to address. While underweight is associated with micro-nutrient deficiencies and infectious diseases such as diarrhea and cholera, overweight and obesity increase the risk of non-communicable diseases (NCDs) such as diabetes, hypertension, coronary heart disease, stroke and certain types of cancer; NCDs were responsible for more than 650 per 100,000 deaths in 2014 in the African region (World Health Organization, 2014). Being a growing public health concern, obesity is now recognized as a global epidemic and is of great interest for economists (Flegal, 2006).

On the one hand, several research works in (health and labor) economics focus on the direct and indirect costs of obesity, and more globally of NCDs, for society (Cawley, 2015; Currie, 2009), by measuring its impacts on health expenditures and socioeconomic success such as 
employment, labor productivity, earnings and school attainment. On the other hand, another research avenue in (health and development) economics focuses on the socioeconomic drivers of overweight and obesity. Indeed, it is well-known that households or individual socioeconomic status (SES), measured by education, income, wealth and/or occupation, are strong determinants of health-related behaviors and nutritional outcomes (Sobal \& Stunkard, 1989). Interestingly, the association between SES and BMI is highly heterogeneous, depending on the level of economic development in the country, regions, and gender concerned. In her literature review, McLaren (2007) concludes that the association tends to be negative in rich countries like the US, especially among women living in urban areas, whereas the opposite could be true in poor and traditional societies such as in most SSA countries, especially among men. For Renzaho (2004), the positive association assumed in African societies reflects the valorization of excess weight as a sign of beauty, health and prosperity. However, changes in weight perception in Africa are observed in the recent literature, nuancing the presumed preference for large body shape. For instance, in an anthropological study in a Cameroonian community that traditionally appreciated overweight, Cohen et al. (2013) observed increasing social rejection of excess weight among women, who wished to lose weight and whose aesthetic criteria were more oriented towards thinness. Moreover, quantitative studies are beginning to put forward a shift in the association between SES and bodyweight outcomes, particularly in upper middle income countries such as South Africa (Jones-Smith et al., 2012). Likewise, recent studies focusing on lower middle income countries in SSA produced mixed results: half reporting positive associations, and half reporting non-significant associations, nonlinear associations and sometimes even negative associations (Daran et al., 2020; Onubi et al., 2016). Hence, one can assume that the social distribution of overweight is globally changing in SSA, at least for women and in middle income countries. At the turn of the $21^{\text {st }}$ century, the association between SES and BMI in SSA may have been transformed into a non-linear 
relationship, more difficult to capture in the absence of more sophisticated econometric approaches.

Focusing on adult women (18-49 years old) in 36 SSA countries, this article provides updated investigations of the relationship between SES indicators, measured by individual schooling attainment and household wealth, and bodyweight outcomes, measured by BMI. This work represents three main contributions. First, we pool a large sample of cross-sectional demographic and health household surveys offering a diversified picture of SSA over time (from 1990 to 2019). This procedure allows us to: (i) explore the heterogeneous development of countries and populations in SSA regarding the nutrition transition, and (ii) understand how this heterogeneity influences the SES-BMI relationship. We assume stronger changes in the relationship among richer SSA countries (i.e., middle income countries) and the most recent survey waves. Second, to capture the potential presence of nonlinearities in the relationship, we systematically compare linear, quadratic, and categorical specifications of SES indicators. In line with the literature based on the richest SSA countries (Stringhini et al., 2013; Wariri et al., 2021) and other middle income countries such as China and Mexico (e.g., Bonnefond \& Clément, 2014; Levasseur, 2015), we assume that the SES-BMI relationship tends to follow a U-inverted form, given the emergence of a middle class that could be associated with Western lifestyles and weight gain (i.e., a social reversal of obesity). ${ }^{3}$ Third, unlike previous studies published in epidemiological journals (for a review see Onubi et al., 2016 and Yiga et al., 2020), we combine standard multivariate regressions based on ordinary least square (OLS) estimations and instrumental variables (IV) to deal with potential reverse causality and the presence of unobserved heterogeneity that may bias the estimates. For example, in SSA, individuals with a high BMI may be perceived more positively in job interviews than their thinner counterparts, the latter being perceived as sick, and may thus obtain work more easily and thereby obtain a regular income. Such an endogeneity issue (i.e., omission of weight-based perceptions and 
reverse causality) could overstate the positive associations between SES and bodyweight reported in several epidemiological studies. To provide endogeneity-robust conclusions, we tested several sets of instruments to fix unobserved BMI variations potentially correlated with SES.

This article is organized as follows. In Section 2, we present the methods we used to empirically analyze the relationship between SES and BMI in SSA. In Section 3, we introduce some descriptive statistics and comment the results of the OLS and IV regressions. We also explore potential heterogeneous effects according to the survey waves and a country's level of economic development. Finally, in Section 4, we discuss our main findings, conclude, and mention some limitations and policy recommendations.

\section{Methods}

\subsection{Data and sample}

The Demographic and Health Survey (DHS) program has collected and disseminated nationally representative data on several topics, including nutrition, health, and population trends, through more than 400 surveys in over 90 developing countries since 1985 . The DHS program was funded by the US Agency for International Development (USAID) and supported by multiple donors and funds. Using face-to-face interviews at the household level, the DHS program collected data that are comparable across countries based on standard model questionnaires. In all households, women age 15-49 were eligible to participate. In this study, we merged data from the household questionnaire and the women's individual questionnaire for each country of SSA (including usually between 5,000 and 30,000 households per survey) and each available wave (typically conducted at about 5-year intervals in each country). Since 1985, seven waves of surveys have been conducted: wave 1 lasted from 1985 to 1990; wave 2 from 1990 to 1997; wave 3 from 1994 to 2001; wave 4 from 1997 to 2005; wave 5 from 2005 to 2010, wave 6 from 2010 to 2016; and wave 7 from 2015 to 2019 (wave 8 is ongoing). Each 
survey wave uses a similar sampling approach based on two-stage probability samples to reduce sampling errors, typically stratified by geographic region and rural-urban areas. ${ }^{4}$

Unfortunately, the DHS program does not provide data about five countries in SSA (Guinea-Bissau, Mauritius, Seychelles, Somalia, and South Sudan). Moreover, adult anthropometric measurements (e.g., height and weight) are not available for seven additional countries (Angola, Botswana, Cabo Verde, Equatorial Guinea, Eritrea, Mauritania, and Sudan). Likewise, anthropometric measures are only available from wave 2 to wave 7 for women aged 15 to 49 . Given the small proportion of surveys including anthropometric data for men and older individuals (up to 64), we decided to focus on women younger than 50. As a result, our final sample covers 36 SSA countries from 1990 to 2019, as shown in Figure 1. For the 36 countries and 6 waves considered, once the women datasets were appended and the household member datasets merged, our final metabase comprises 1,386,760 female individuals (aged 1564) and 8,140 households. Since our analysis focuses on female adults, we excluded pregnant and lactating women, minor women aged between 15 and 17, and women older than 49 years old to limit anthropometric biases, which reduced the number of observations to 713,085 . Furthermore, we removed female individuals with missing or extreme BMI values, i.e., where $\mathrm{BMI} \geq 50 \mathrm{~kg} / \mathrm{m}^{2}$ or BMI $\leq 12 \mathrm{~kg} / \mathrm{m}^{2}$. Our final restricted sample thus comprises 392,846 adult women (aged 18-49). 


\section{Figure 1: Map of the sample}

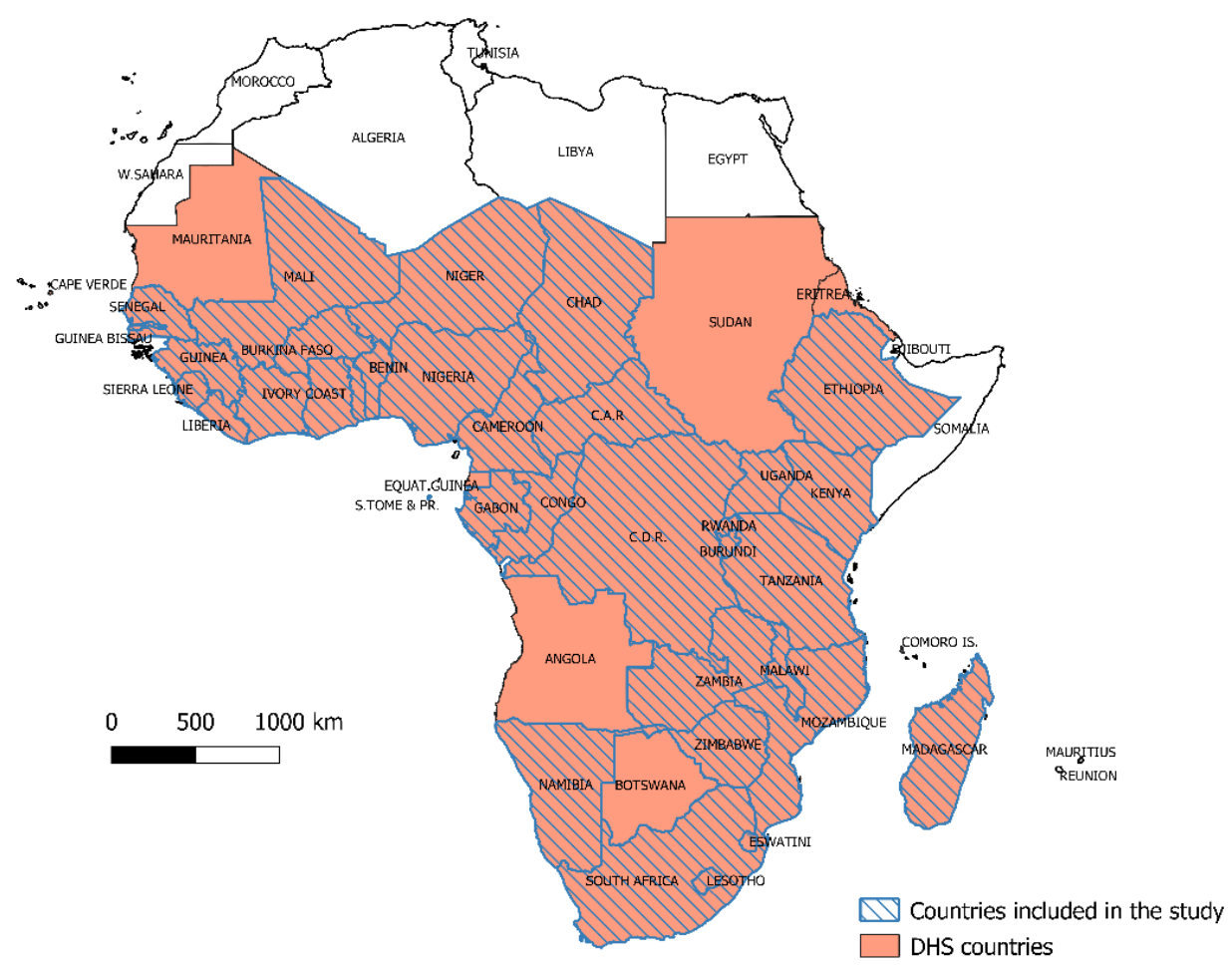

Source: Authors' computation using DHS data for SSA (1990-2019).

As suggested by the DHS administration and related literature, we use DHS sample weights in all our analyses to make sample data representative of the entire population (Benedict et al., 2018). Specifically, because we compare DHS samples from different waves and different countries, we had to de-normalize our dataset. Hence, we created a new sample weight by multiplying the initial weight by the total number of females aged 15 to 49 in the country at the time of the survey, and then by dividing this result by the number of women aged 15 to 49 interviewed in this survey. ${ }^{5}$ In addition, we differentiated cluster and strata variables across years and countries. Finally, we applied the normal complex design sample procedure with these redefined variables. Our metabase can consequently be used to compare country and year estimates.

\subsection{OLS model}

In line with Pieroni \& Salmasi (2010) and Bonnefond \& Clément (2014), we adopt a reduced-form model that regresses female bodyweight (measured by $\mathrm{BMI}$, in $\mathrm{kg} / \mathrm{m}^{2}$ ) on its 
indirect determinants, i.e., SES, individual characteristics (e.g., age, current marital status, number of children, and smoking) and built environment (e.g., housing and living area characteristics); omitting the direct determinants of weight gain, i.e., food intakes and energy expenditures. According to Krieger et al. (1997), two dimensions are fundamental to define the socioeconomic position of an individual in society: actual resources (e.g., household income) and prestige (which depends on household wealth, and individual occupation and education attainment). Given the lack of earning information in DHS data, here we only analyze the prestige dimension, by measuring women's SES by the level of completed education and wealth indicators.

We first regress pooled OLS estimations systematically controlling for country and time fixed effects, as follows.

$$
\text { (1) } \mathrm{BMI}_{\mathrm{i}}=\beta_{0}+\beta_{1} \mathrm{SES}_{\mathrm{i}}+\beta_{2} \mathrm{X}_{\mathrm{i}}+a_{1}+a_{2}+a_{1} a_{2}+\varepsilon_{\mathrm{i}}
$$

where $\mathrm{BMI}_{\mathrm{i}}$ is the dependent variable measured for each non-pregnant non-lactating woman $i$ aged 18 to 49. The explanatory variable of interest is $\mathrm{SES}_{\mathrm{i}}$, referring to education and wealth factors for each individual $i$. In linear specifications of Eq. 1, we use as SES indicators: years of education of each individual $i$ (a discrete variable ranging from 0 to 26 years), and an owned asset index measured at the household level (a discrete variable ranging from 0 to 7 owned assets). We constructed the owned asset index by counting (adding 1 if the household has the asset, 0 otherwise) whether the household has or not: (i) electricity, (ii) a radio, (iii) a television, (iv) a refrigerator, (v) a bicycle, (vi) a motorcycle, and (vii) a car. Then, in order to test for potential nonlinearities in the SES-BMI relationship, we successively use quadratic, and categorical specifications for both wealth and education dimensions. In quadratic specifications, we added the respective squares of previous education and wealth indicators in the set of regressors. In categorical specifications, for education and wealth we use respectively: a 
categorical variable of educational attainment identifying the highest level of schooling achieved by the individual $i$ (four dummy categories: no education, primary, secondary, higher education), and a categorical wealth index measured in quintiles (poorest, poorer, middle, richer, richest) based on a principal component analysis (directly implemented by the DHS administrators) mixing information about household owned assets (listed above), the material used to build their home, water accessibility and sanitation facilities. Note that the wealth index is only available from wave 4 to wave 7.

$\mathrm{X}_{\mathrm{it}}$ refers to the set of control variables. In line with Clément (2017), we control female BMI variations for individual age (in years) and its square (a proxy of metabolic change), individual marital status (in an union or not), individual smoking practice (smoking or not), the number of children in the household, the number of rooms for sleeping in the household, and the level of urbanization of the area of residence (urban or rural). Finally, $a_{1}$ and $a_{2}$ refer to time fixedeffects (for the 29 survey years, ranging from 1990 to 2019) and country fixed-effects (for the 36 countries included in the sample), respectively. $a_{1} a_{2}$ is their mutual interactions to control for BMI differences across countries and time, and make all surveys comparable. Finally, $\beta_{0}$ and $\varepsilon_{\mathrm{it}}$ are respectively the intercept and the unknown error term.

\subsection{IV model}

Although previous OLS regressions can provide information concerning the form of the association between SES and female BMI, these estimates could be biased because of the presence of endogeneity in Eq.1. As explained earlier, two sources of bias make the SES-BMI relationship highly endogenous: the existence of reverse causality and the omission of unobserved heterogeneity correlated with SES. Mathematically, these biases occur when the residuals from Eq.1 $\left(\varepsilon_{\mathrm{i}}\right)$ are correlated with SES indicators. A standard way to deal with potential endogeneity relies on the introduction of exogenous variations uncorrelated with BMI 
but highly mediated by SES, i.e., an IV approach. To implement IV correction, we used a pooled two-stage least square (2SLS) estimation model as follows. ${ }^{6}$

$$
\text { (2) }\left\{\begin{array}{c}
\mathrm{BMI}_{\mathrm{i}}=\delta_{0}+\delta_{1} \widehat{\mathrm{SES}_{1}}+\delta_{2} \mathrm{X}_{\mathrm{i}}+a_{1}+a_{2}+\partial_{\mathrm{i}} \\
\text { with } \mathrm{SES}_{\mathrm{i}}=\gamma_{0}+\gamma_{1} \mathrm{IV}_{\mathrm{i}}+\gamma_{2} \mathrm{X}_{\mathrm{i}}+a_{1}+a_{2}+\mathrm{u}_{\mathrm{i}}
\end{array}\right.
$$

The first step of Eq.2 (bottom line) regresses SES on the set of control variables $\left(\mathrm{X}_{\mathrm{i}}\right)$ and a vector of exogenous variables called the instruments $\left(\mathrm{IV}_{\mathrm{i}}\right)$. Assuming the instruments are exogenous and relevant, the first step regression enables estimation of SES values uncorrelated with unobserved BMI variations. The exogenous predictions of SES calculated in the first step regression $\left(\widehat{\mathrm{SES}_{1}}\right)$ are then introduced in the structural regression (upper line of Eq.2). Hence, $\delta_{1}$ refers to an unbiased fitted effect of SES on BMI, transiting through an exogenous instrument.

To be valid, instruments must meet two conditions: (i) be a strong predictor of SES (relevance condition) but (ii) be uncorrelated with unobserved variations in female BMI (exogeneity condition, i.e., uncorrelated with $\varepsilon_{\mathrm{i}}$ or $\partial_{\mathrm{i}}$ ). In the existing literature, two types of instruments are commonly used to instrument SES and assess its effects on individual BMI. A first group of studies used the share of household income unrelated to work as instruments, like social safety nets or family transfers (Cawley et al., 2010; Schmeiser, 2009). However, recent findings suggest that such instruments potentially violate the exogeneity condition insofar as enrollment in social protection may significantly affect participants' BMI (Levasseur, 2019). In any case, DHS data do not provide information about external sources of income transferred to households. A second group of studies relies on the use of state or community socioeconomic and demographic variables as instruments (Kim et al., 2010; Barnes et al., 2013; Kpelitse et al., 2014; Bonnefond et al., 2014; Clément, 2017), considering that such aggregated factors are potentially good instruments because they are beyond the control of individuals and households, and can thus be treated as exogenous. 
In line with the second group of studies, we first run Eq.2 using local demographic characteristics as instruments. Specifically, we use as IV the proportion per locality (at the PSU level) of houses fitted with a processed floor (i.e., made of wood planks, parquet, vinyl, ceramic tiles, cement, or carpet) compared to floors left in their original states (i.e., made of earth, sand, or dung). Regarding the relevance condition, one can reasonably assume that the area percentage of houses with processed floors is positively correlated with household wealth and individual education, since the modernity and appearance of the home are factors of affluence and prosperity in Africa (Pellow, 2015). In addition, this proportion informs about the level of development of the area, which is likely to be associated with the availability of educational or sanitary facilities that allow the inhabitants to increase their schooling attainment (Shabaya et al., 2004; Tusting et al., 2015). Empirically, both the proportion of processed floor material and its square are significantly and positively correlated with household wealth indicators and female education, at the $1 \%$ level (see first-stage estimates available in Table $\mathrm{S} 1$ in Supplementary Materials). Likewise, the F-statistic against the null hypothesis that the excluded instruments are irrelevant in the first-stage estimates is larger than 10 , meaning that the instruments are strong predictors of SES (Angrist \& Pischke, 2008). In addition, R-squares are very high (around 40\%), underlining the good specification of the model. Unfortunately, the exogeneity condition is not really testable and can always be questioned. However, there is no reason to think that the proportion of processed floor (at home) in the community will directly affect female BMI by other pathways than household wealth or individual education. Hence, we can assume that this instrument is reliable and meets the conditions of relevance and exogeneity.

In agreement with Angrist et al. (2008), we also test the consistency of IV estimates using alternative instruments that capture less aggregated variations: an individual's religious affiliation and the country specific micro-ethnic rank of individuals in society. An individual's 
religious affiliation is measured through five categories: Muslim, Catholic, Protestant, other religions, and no religious affiliation (reference group). The religion variable is potentially a good IV because of a strong correlation with SES. First, a definite relationship between religious background and SES has been detected in the literature. For example, Heaton (2013) shows that religious affiliation is associated with education and wealth, specifically in developing countries, although the relationship varies across countries. Comparing Muslim and Christian women, the authors observe that the former tend to be less educated than the latter in Ghana, Nigeria, Cameroon, and Kenya, whereas the opposite is the case in Madagascar, Rwanda, and Uganda. In contrast, Protestants tend to be wealthier than Muslims and Christians in Nigeria, Ghana, and Zimbabwe. Our empirical tests are consistent with those of Heaton (2013). In the first-stage estimates reported in Table S1 in Supplementary Materials, each fitted coefficient of religion dummies is significant at the $1 \%$ level. In addition, the F-statistics on the excluded instruments are systematically higher than 10 (i.e., religion is a strong instrument). Once again, we are not able to empirically test the exogeneity condition but are reasonably confident when referring to previous studies. In the long term, studies that analyze potential impacts of food-related events such as fasting (e.g., Ramadan or Lent) found no significant effect on individual weight (Hajek et al., 2012). In Hajek et al. (2012), a slight weight loss was observed during the Ramadan fast but the original weight was regained one month later.

Finally, the individual ethnic-rank in society is measured using five alternatives. The respondent can belong to the first (reference group), the second or the third major ethnic group in the country, or to an ethnic minority, or the respondent is a foreigner. According to Franck et al. (2012), decision makers largely favor major ethnic groups in SSA, especially in educationrelated dimensions. Similarly, major African ethnic groups are often overrepresented in the elite class (Ngaruko \& Nkurunziza, 2000). Hence, belonging to the major ethnic groups in a country is assumed to be positively and strongly correlated with SES. As shown in Table S1 in 
Supplementary Materials, both first-stage estimates and F-statistics on excluded instruments confirm this intuition and suggest convincing results. However, regarding the exogeneity condition, this third instrument is more questionable than the first two. In nutrition science, the epidemiological literature reports differences in BMI and fat concentration across macro-ethnic groups (across Caucasian, African, Hispanic and Asian populations), considering the metabolic factors in each macro-ethnic group to be relatively homogenous (Carroll et al., 2008; Merwe \& Pepper, 2006). Although the African macro-ethnic group (which concerns almost all the SSA population, with the exception of South Africa) is considered as relatively homogenous in terms of metabolism by this epidemiological literature, other studies found a link between African micro-ethnic groups and obesity (Biritwum et al., 2005). In fact, African micro-ethnic groups may have different weight-based perceptions and preferences, which might correlate with calorie intake and energy expenditure, and hence with female BMI (Cohen et al., 2013). Nonetheless, as mentioned by Cohen et al. (2013), traditional perceptions of weight and beauty tend to disappear across time, economic development and urbanization in SSA, in favor of the adoption of Western thinness ideals. Hence, even if imperfect, the use of individual ethnicranks in society as an alternative instrument may be relevant once area characteristics (e.g., region, locality, and urbanicity) are controlled for, assuming that the ethnic rank in society mainly affects BMI transiting through socioeconomic factors such as education, wealth, and income. We are aware of the heaviness of this assumption and remain cautious about the acceptance of the exogeneity condition. This is why we only use ethnic ranks in society as additional instruments, in combination with religious affiliation, to regress categorical specifications of SES. Indeed, IV models need at least as many instruments as endogenous regressors to be implemented.

\section{Results}

\subsection{Descriptive statistics}


Table 1 lists and classifies the 36 SSA countries selected for the analysis (data obtained in survey waves 2 to 7 ) according to the national income groups defined by the World Bank (The World Bank, 2019). Table 1 focuses on non-pregnant non-lactating female adults and also reports sample means of the main variables of interests (i.e., BMI, education, and wealth) for each selected country. In Table 1, we observe that the average BMI per country tends to be higher among upper middle income countries and lower among low income countries. Although more fluctuating, a similar trend is observed for both the level of education (in number of years) and the composite index of owned assets (varying from 0 to 7).

Table 1: Sample characteristics

\begin{tabular}{|c|c|c|c|c|}
\hline Country & Observations & $\begin{array}{c}\text { Mean BMI } \\
\left(\text { in } k g / \mathbf{m}^{2}\right)\end{array}$ & $\begin{array}{c}\text { Mean years of } \\
\text { completed } \\
\text { education }\end{array}$ & $\begin{array}{c}\text { Mean asset } \\
\text { index } \\
\text { (0-to-7 score) }\end{array}$ \\
\hline \multicolumn{5}{|l|}{ Upper middle income countries } \\
\hline Gabon & 4,757 & 25.28 & 8.07 & 3.07 \\
\hline Namibia & 10,392 & 23.95 & 8.59 & 2.61 \\
\hline South Africa & 2,621 & 28.72 & 10.40 & 3.43 \\
\hline Total & 17,770 & 28.04 & 10.10 & 3.33 \\
\hline \multicolumn{5}{|l|}{ Lower middle income countries } \\
\hline Benin & 23,691 & 23.59 & 2.89 & 2.44 \\
\hline Republic of the Congo & 7,066 & 23.57 & 7.81 & 1.77 \\
\hline Côte d'Ivoire & 5,133 & 23.19 & 3.59 & 2.56 \\
\hline Cameroon & 11,766 & 24.73 & 7.00 & 2.39 \\
\hline Ghana & 9,819 & 24.17 & 6.93 & 2.52 \\
\hline Kenya & 20,039 & 23.58 & 8.05 & 1.85 \\
\hline Comoros & 333 & 24.43 & 6.51 & 2.53 \\
\hline Lesotho & 6,878 & 26.06 & 8.08 & 1.60 \\
\hline Nigeria & 48,609 & 23.40 & 6.85 & 2.72 \\
\hline Senegal & 6,278 & 22.65 & 2.98 & 2.55 \\
\hline Sao Tome and Principe & 1,372 & 24.58 & 5.57 & 2.82 \\
\hline Swaziland & 3,155 & 27.29 & 8.37 & 2.40 \\
\hline Tanzania & 1,989 & 23.45 & 5.94 & 1.68 \\
\hline Zambia & 18,195 & 22.91 & 6.91 & 2.04 \\
\hline Zimbabwe & 20,804 & 24.35 & 8.62 & 2.03 \\
\hline Total & 206,025 & 23.58 & 6.77 & 2.36 \\
\hline \multicolumn{5}{|l|}{ Low income countries } \\
\hline Burkina Faso & 10,863 & 21.65 & 1.81 & 2.44 \\
\hline Burundi & 5,702 & 21.26 & 4.19 & 1.01 \\
\hline Democratic Republic of Congo & 5,952 & 22.08 & 6.19 & 1.39 \\
\hline Central African Republic & 445 & 21.23 & 3.01 & 1.02 \\
\hline Ethiopia & 26,617 & 20.65 & 3.23 & 0.97 \\
\hline Gambia & 2,185 & 23.18 & 5.31 & 3.04 \\
\hline Guinea & 813 & 23.01 & 2.49 & 1.98 \\
\hline Liberia & 6,176 & 23.50 & 4.28 & 0.99 \\
\hline Madagascar & 9,583 & 20.94 & 4.85 & 1.50 \\
\hline Mali & 16,259 & 22.95 & 1.97 & 2.54 \\
\hline Malawi & 18,583 & 22.60 & 4.82 & 1.36 \\
\hline Mozambique & 13,346 & 22.80 & 3.39 & 1.67 \\
\hline Niger & 5,627 & 21.71 & 1.11 & 1.12 \\
\hline Rwanda & 13,825 & 22.60 & 4.55 & 1.02 \\
\hline Sierra Leone & 6,415 & 23.46 & 3.19 & 1.28 \\
\hline Chad & 6,868 & 21.30 & 1.79 & 1.07 \\
\hline Togo & 3,148 & 24.33 & 4.86 & 2.51 \\
\hline
\end{tabular}


Notes: While DHS data from 1990 to 2019 are considered, the national income groups rely on the current classification of the World Bank defined in 2019. All digits are weighted according to the DHS complex design.

Source: Authors' calculation using DHS data for SSA (1990-2019).

Table 2 lists descriptive statistics regarding the education-BMI relationship among SSA women (aged 18-49). This table summarizes the results reported in most epidemiological studies quite well. At first sight, Table 2 shows that excess weight is a major concern for the most educated women, as reported by Agyemang et al. (2015). Likewise, as expected, average BMI tends to increase with the level a country's economic development, with alarming levels among lower middle income countries (average BMI being around the $25 \mathrm{~kg} / \mathrm{m}^{2}$ overweight cut-off for the most educated women) and hazardous levels among upper middle income countries (average BMI being between the $25 \mathrm{~kg} / \mathrm{m}^{2}$ overweight cut-off and the $30 \mathrm{~kg} / \mathrm{m}^{2}$ obesity cut-off); which is consistent with the nutrition transition theory (see endnote 2). Moreover, the gap in average BMI across education levels depends to a great extent on the level of a country's economic development: the smallest gap being among upper middle income countries $\left(+1.51 \mathrm{~kg} / \mathrm{m}^{2}\right)$, and the biggest gap being among lower middle income countries $\left(+2.94 \mathrm{~kg} / \mathrm{m}^{2}\right)$.

Table 2: Average female BMI (in $\mathrm{kg} / \mathrm{m}^{2}$ ) per level of completed education

\begin{tabular}{|c|c|c|c|c|}
\hline & $\begin{array}{c}\text { No } \\
\text { education } \\
\end{array}$ & $\begin{array}{c}\text { Primary } \\
\text { education }\end{array}$ & $\begin{array}{l}\text { Secondary } \\
\text { education }\end{array}$ & $\begin{array}{c}\text { Higher } \\
\text { education }\end{array}$ \\
\hline \multicolumn{5}{|c|}{ Per economic development category } \\
\hline Low income countries & 21.05 & 21.98 & 22.74 & 23.17 \\
\hline Lower middle income countries & 22.34 & 23.63 & 23.98 & 25.28 \\
\hline Upper middle income countries & 27.01 & 27.19 & 28.14 & 28.52 \\
\hline \multicolumn{5}{|l|}{ Per urban level } \\
\hline Rural & 23.52 & 24.44 & 24.49 & 25.10 \\
\hline Urban & 21.21 & 22.44 & 23.29 & 24.73 \\
\hline \multicolumn{5}{|l|}{ Per survey wave } \\
\hline Wave 1 & na & na & na & na \\
\hline Wave 2 & 21.28 & 22.11 & 23.39 & 24.63 \\
\hline Wave 3 & 21.52 & 22.41 & 23.27 & 23.94 \\
\hline Wave 4 & 21.31 & 22.83 & 23.25 & 24.77 \\
\hline Wave 5 & 22.09 & 23.19 & 23.60 & 24.80 \\
\hline Wave 6 & 21.99 & 23.23 & 23.93 & 24.84 \\
\hline Wave 7 & 21.89 & 23.67 & 25.48 & 25.72 \\
\hline All countries (whole sample) & 21.74 & 23.11 & 24.01 & 25.01 \\
\hline
\end{tabular}

Notes: While DHS data from 1990 to 2019 are considered, the national income groups rely on the current classification of the World Bank defined in 2019. na for "not available".

Source: Authors' calculation using DHS data for SSA (1990-2019). 
Further interesting results appear when BMI trends are considered over time. As shown in Table 2, between wave 2 and wave 7 (i.e., from the 1990s on), the biggest increase in average BMI was among intermediate levels of education, with a respective 1.6 and $2.1 \mathrm{~kg} / \mathrm{m}^{2}$ increase in women who completed primary and secondary school grades. In comparison, the average BMI has increased by 0.6 and $1.1 \mathrm{~kg} / \mathrm{m}^{2}$ for women with no formal education and women with a high level of completed education, respectively. This unequal weight gain across education levels is consistent with several research works that reported significant changes in food habits vehicled by the emergence of an African middle class. Among intermediate levels of SES, these studies report increased consumption in non-essential products (e.g., carbonated soft drinks and candy) and high fat density calorie animal proteins (e.g., meat and dairy) versus reduced consumption of starchy staple foods richer in fibers (CFAO et al., 2016; May, 2018; Tschirley et al., 2015).

\subsection{Main econometric results}

Based on Eq.1 and Eq.2, both OLS and IV regressions are run to determine how education and wealth indicators influence female adult BMI in SSA. Table 3 and Table 4 test for both linear and quadratic specifications of both SES indicators, the former relying on years of completed education and the latter on the owned asset index. Table 5 tests for a categorical specification of education and wealth indicators, using the highest schooling level completed by an individual and quintiles of the wealth index. In each reported regression, the entire set of control variables is taken into account, including time and country fixed effects. As shown by R-square values in OLS regressions (e.g., Table 3), the explanatory power of the model is correct, capturing more than $20 \%$ of variations in the BMI. Moreover, the fitted coefficients of most control variables are consistent with the existing literature that analyzes the causes of female obesity in developing countries (e.g., Clément, 2017; Levasseur, 2015), and more specifically in SSA (Onubi et al., 2016). ${ }^{7}$ 
Regarding the influence of education and wealth indicators on female BMI, OLS regressions in Tables 3 and 4 report interesting results. While linear specifications of both SES indicators globally suggest positive links, quadratic OLS regressions identify the presence of a turning point in the association, which could be located at the end of the distribution (i.e., a concave downward shape). In Tables 3 and 4, IV-corrections confirm the presence of a turning point in the SES-BMI relationship. ${ }^{8}$ For each set of instruments, Table 3 indicates a curvilinear effect of the number of years of education on female BMI. It is reassuring to note that the use of our preferred instrument (IV1) reports the most consistent and convincing results, with a similar turning point to the one found in OLS regression (around 16 years of completed education, Table 3 Column 4). Considering a categorical specification of female education, Table 5 confirms this nonlinear finding, stressing the protective effect of high levels of education against weight gain. Compared to non-educated women, women who completed their secondary education have the largest BMI while women with high education are the thinnest (Table 5).

In contrast, Table 4 depicts a more complex relationship between household wealth and female BMI in SSA. While the use of IV2 and IV3 suggests a positive effect of the household owned asset index on female BMI, the use of IV1 results in a U-inverted effect as observed for education, with a turning point occurring around 3.6 owned assets (Column 4). Interestingly, using a categorical measurement of wealth (i.e., the wealth quintile provided by the DHS administration), Table 5 highlights - an even more - nonlinear trend between wealth and BMI, explaining why Table 4 provides different results depending on the instruments used. According to Table 5, the effects of wealth quintiles on female BMI seem to follow an N-shape pattern. Compared to the most deprived households (Q1), women in middle wealth households (Q3) have the highest BMI, while the wealthiest women (Q5) are thinner than the latter but larger than the former. 


\subsection{Further investigation of heterogeneous effects}

Using the same econometric strategy, we explore potential heterogeneous effects of SES indicators on female BMI according to the DHS wave and the level of a country's economic development (based on the 2019's World Bank classification). We respectively report OLS and IV regressions (only considering our preferred instruments IV1) for time specific subsamples (wave 2 to wave 7) and development specific subsamples (low income to higher middle income countries) in Tables S2 and S3 in Supplementary Materials. Table S2 shows that the SES-BMI relationship changes from positive to curvilinear (concave) from wave 4 for women, i.e., from 1997. This finding emphasizes the occurrence of a social shift of the obesity burden in SSA. Table S3 further suggests that, once an IV-correction is implemented, the curvilinear associations between SES indicators and female BMI systematically remain significant in lower middle income countries in SSA. In contrast, the results appear less robust in the subsamples of low income countries and higher middle income countries. Note that the limited number of observations for higher middle income countries may explain the lack of robustness. 
Table 3: Results of OLS and IV regressions using education as SES indicator

\begin{tabular}{|c|c|c|c|c|c|c|c|c|}
\hline \multirow{2}{*}{ Dependent variable: female BMI } & \multicolumn{2}{|c|}{ OLS } & \multicolumn{2}{|c|}{ IV 1} & \multicolumn{2}{|c|}{ IV 2} & \multicolumn{2}{|c|}{ IV 3} \\
\hline & Linear & Quadratic & Linear & Quadratic & Linear & Quadratic & Linear & Quadratic \\
\hline \multirow{2}{*}{ Years of completed education } & $0.170^{* * *}$ & $0.250 * * *$ & $0.543 * * *$ & $0.890 * * *$ & $0.277 * * *$ & $2.251 * *$ & $0.263 * * *$ & $1.308^{* * *}$ \\
\hline & $(0.00416)$ & $(0.0107)$ & $(0.0159)$ & $(0.122)$ & $(0.0131)$ & $(1.113)$ & $(0.0125)$ & $(0.343)$ \\
\hline \multirow{2}{*}{$\begin{array}{l}\text { Square of years of completed } \\
\text { education }\end{array}$} & & $-0.00595 * * *$ & & $-0.0272 * * *$ & & $-0.169 *$ & & $-0.0882 * * *$ \\
\hline & & $(0.000771)$ & & $(0.00954)$ & & $(0.0954)$ & & $(0.0290)$ \\
\hline \multirow{2}{*}{ Age } & $0.339 * * *$ & $0.351 * * *$ & $0.249 * * *$ & $0.311 * * *$ & $0.279 * * *$ & $0.750 * * *$ & $0.296 * * *$ & $0.555 * * *$ \\
\hline & $(0.0125)$ & $(0.0127)$ & $(0.0137)$ & $(0.0259)$ & $(0.0127)$ & $(0.265)$ & $(0.0138)$ & $(0.0873)$ \\
\hline \multirow[t]{2}{*}{ Square of age } & $-0.00346^{* * *}$ & $-0.00361 * * *$ & $-0.00205^{* * *}$ & $-0.00279 * * *$ & $-0.00262 * * *$ & $-0.00845^{* *}$ & $-0.00284 * * *$ & $-0.00607 * * *$ \\
\hline & $(0.000188)$ & $(0.000190)$ & $(0.000205)$ & $(0.000337)$ & $(0.000191)$ & $(0.00329)$ & $(0.000207)$ & $(0.00110)$ \\
\hline \multirow[t]{2}{*}{ Marital status (Ref: Single) } & $0.787 * * *$ & $0.786 * * *$ & $1.340 * * *$ & $1.308 * * *$ & $0.922 * * *$ & 0.420 & $0.923 * * *$ & $0.661 * * *$ \\
\hline & $(0.0378)$ & $(0.0379)$ & $(0.0457)$ & $(0.0476)$ & $(0.0398)$ & $(0.294)$ & $(0.0434)$ & $(0.102)$ \\
\hline \multirow[t]{2}{*}{ Number of children } & $-0.0588 * * *$ & $-0.0656 * * *$ & $0.126 * * *$ & $0.0849 * * *$ & 0.0139 & $-0.346^{*}$ & -0.00206 & $-0.185 * * *$ \\
\hline & $(0.00868)$ & $(0.00869)$ & $(0.0120)$ & $(0.0186)$ & $(0.0108)$ & $(0.206)$ & $(0.0113)$ & $(0.0622)$ \\
\hline \multirow[t]{2}{*}{ Smoking (Ref: No) } & $1.088 * * *$ & $1.072 * * *$ & $0.541 * * *$ & $0.496^{* * *}$ & $0.913 * * *$ & $0.599 * * *$ & $0.891 * * *$ & $0.730 * * *$ \\
\hline & $(0.109)$ & $(0.109)$ & $(0.117)$ & $(0.118)$ & $(0.0935)$ & $(0.218)$ & $(0.121)$ & $(0.142)$ \\
\hline \multirow[t]{2}{*}{ Number of rooms } & $0.0640 * * *$ & $0.0674 * * *$ & $0.0343 * * *$ & $0.0515 * * *$ & $0.0451 * * *$ & $0.153 * *$ & $0.0408 * * *$ & $0.0926 * * *$ \\
\hline & $(0.0102)$ & $(0.0102)$ & $(0.0106)$ & $(0.0123)$ & $(0.0103)$ & $(0.0615)$ & $(0.0110)$ & $(0.0217)$ \\
\hline \multirow[t]{2}{*}{ Currently working (Ref: No) } & $0.391 * * *$ & $0.380 * * *$ & $0.233 * * *$ & $0.189 * * *$ & $0.378 * * *$ & 0.0984 & $0.367 * * *$ & $0.159 * *$ \\
\hline & $(0.0322)$ & $(0.0321)$ & $(0.0360)$ & $(0.0384)$ & $(0.0320)$ & $(0.161)$ & $(0.0351)$ & $(0.0777)$ \\
\hline \multirow[t]{2}{*}{ Living area (Ref: Urban) } & $-1.454 * * *$ & $-1.457 * * *$ & $-0.323 * * *$ & $-0.399 * * *$ & $-1.076^{* * *}$ & $-2.158 * * *$ & $-1.099 * * *$ & $-1.600 * * *$ \\
\hline & $(0.0404)$ & $(0.0405)$ & $(0.0663)$ & $(0.0746)$ & $(0.0589)$ & $(0.625)$ & $(0.0604)$ & $(0.178)$ \\
\hline \multirow[t]{2}{*}{ Constant } & $13.17 * * *$ & $12.88 * * *$ & $13.62 * * *$ & $12.61 * * *$ & $14.80 * * *$ & $8.831 * *$ & $14.50 * * *$ & $11.27 * * *$ \\
\hline & $(0.267)$ & $(0.270)$ & $(0.883)$ & $(0.941)$ & $(0.877)$ & $(3.674)$ & $(0.899)$ & $(1.585)$ \\
\hline Observations & 265,114 & 265,114 & 265,114 & 265,114 & 248,024 & 248,024 & 186,880 & 186,880 \\
\hline R-squared & 0.210 & 0.211 & & & & & & \\
\hline Country FE & YES & YES & YES & YES & YES & YES & YES & YES \\
\hline Year FE & YES & YES & YES & YES & YES & YES & YES & YES \\
\hline Country x Year & YES & YES & NO & NO & NO & NO & NO & NO \\
\hline Excluded instruments & & & $\begin{array}{l}\text { Proportional area of } \\
\text { processed floor }\end{array}$ & $\begin{array}{l}\text { Proportional area } \\
\text { processed floor } \\
\& \text { its square }\end{array}$ & Religion & mies & Religion \& etl & ty dummies \\
\hline J statistic (Sargan-Hansen test) & & & Just-identified & Just-identified & 24.810 & 6.315 & 65.384 & 40.890 \\
\hline $\mathrm{P}$-value & & & & & 0.0000 & 0.0425 & 0.0000 & 0.0000 \\
\hline
\end{tabular}

Note: $* * * \mathrm{p}<0.01, * * \mathrm{p}<0.05, * \mathrm{p}<0.1$. All data are weighted and clustering methods at the PSU-level were applied. Robust standard errors are in parentheses. IV1 is instrumented by the proportion of processed floor material (at home) by PSU, IV2 by religion dummies and IV3 by the combination of religion and ethnicity dummies. Source: Authors' calculation using DHS data for SSA (1990-2019). 
Table 4: Results of OLS and IV regressions using asset index as SES indicator

\begin{tabular}{|c|c|c|c|c|c|c|c|c|}
\hline \multirow{2}{*}{ Dependent variable: female BMI } & \multicolumn{2}{|c|}{ OLS } & \multicolumn{2}{|c|}{ IV 1} & \multicolumn{2}{|c|}{ IV 2} & \multicolumn{2}{|c|}{ IV 3} \\
\hline & Linear & Quadratic & Linear & Quadratic & Linear & Quadratic & Linear & Quadratic \\
\hline \multirow[t]{2}{*}{ Asset index } & $0.535 * * *$ & $0.548 * * *$ & $1.608 * * *$ & $4.908 * * *$ & $3.446 * * *$ & -9.146 & $2.365 * * *$ & -2.424 \\
\hline & $(0.0120)$ & $(0.0298)$ & $(0.0495)$ & $(0.673)$ & $(0.301)$ & $(7.776)$ & $(0.174)$ & $(1.519)$ \\
\hline \multirow[t]{2}{*}{ Square of asset index } & & -0.00230 & & $-0.663 * * *$ & & 2.712 & & $1.022 * * *$ \\
\hline & & $(0.00549)$ & & $(0.131)$ & & $(1.732)$ & & $(0.325)$ \\
\hline \multirow[t]{2}{*}{ Age } & $0.363 * * *$ & $0.363 * * *$ & $0.324 * * *$ & $0.334 * * *$ & $0.223 * * *$ & $0.137^{*}$ & $0.264 * * *$ & $0.231 * * *$ \\
\hline & $(0.0129)$ & $(0.0129)$ & $(0.0139)$ & $(0.0152)$ & $(0.0208)$ & $(0.0742)$ & $(0.0179)$ & $(0.0238)$ \\
\hline \multirow[t]{2}{*}{ Square of age } & $-0.00387 * * *$ & $-0.00387 * * *$ & $-0.00333 * * *$ & $-0.00336 * * *$ & $-0.00192 * * *$ & -0.00103 & $-0.00247 * * *$ & $-0.00212 * * *$ \\
\hline & $(0.000194)$ & $(0.000194)$ & $(0.000206)$ & $(0.000224)$ & $(0.000304)$ & $(0.000891)$ & $(0.000263)$ & $(0.000337)$ \\
\hline \multirow[t]{2}{*}{ Marital status (Ref: Single) } & $0.470 * * *$ & $0.470 * * *$ & $0.302 * * *$ & $0.146^{* *}$ & 0.0336 & $0.646^{*}$ & $0.183 * * *$ & $0.407 * * *$ \\
\hline & $(0.0382)$ & $(0.0384)$ & $(0.0420)$ & $(0.0582)$ & $(0.0738)$ & $(0.368)$ & $(0.0556)$ & $(0.0946)$ \\
\hline \multirow[t]{2}{*}{ Number of children } & $-0.106 * * *$ & $-0.106 * * *$ & $-0.0322 * * *$ & $-0.0363 * * *$ & $0.0875 * * *$ & $0.136^{* *}$ & 0.00499 & 0.0192 \\
\hline & $(0.00878)$ & $(0.00878)$ & $(0.00961)$ & $(0.0105)$ & $(0.0215)$ & $(0.0572)$ & $(0.0148)$ & $(0.0183)$ \\
\hline \multirow[t]{2}{*}{ Smoking (Ref: No) } & $1.154 * * *$ & $1.153 * * *$ & $0.794 * * *$ & $0.553 * * *$ & 0.180 & $1.032 *$ & $0.374 * *$ & $0.724 * * *$ \\
\hline & $(0.113)$ & $(0.113)$ & $(0.120)$ & $(0.139)$ & $(0.162)$ & $(0.532)$ & $(0.156)$ & $(0.211)$ \\
\hline \multirow[t]{2}{*}{ Number of rooms } & $-0.0584 * * *$ & $-0.0580 * * *$ & $-0.333 * * *$ & $-0.194 * * *$ & $-0.775 * * *$ & $-1.573 * * *$ & $-0.509 * * *$ & $-0.811 * * *$ \\
\hline & $(0.0115)$ & $(0.0115)$ & $(0.0192)$ & $(0.0304)$ & $(0.0789)$ & $(0.606)$ & $(0.0468)$ & $(0.126)$ \\
\hline \multirow[t]{2}{*}{ Currently working (Ref: No) } & $0.410 * * *$ & $0.410 * * *$ & $0.315 * * *$ & $0.189 * * *$ & $0.203 * * *$ & $0.711 * *$ & $0.326 * * *$ & $0.561 * * *$ \\
\hline & $(0.0329)$ & $(0.0328)$ & $(0.0360)$ & $(0.0454)$ & $(0.0504)$ & $(0.326)$ & $(0.0432)$ & $(0.0957)$ \\
\hline \multirow[t]{2}{*}{ Living area (Ref: Urban) } & $-1.227 * * *$ & $-1.226 * * *$ & $0.309 * * *$ & $0.331 * * *$ & $3.087 * * *$ & $4.056^{* * *}$ & $1.389 * * *$ & $1.718^{* * *}$ \\
\hline & $(0.0440)$ & $(0.0439)$ & $(0.0869)$ & $(0.0997)$ & $(0.461)$ & $(1.366)$ & $(0.262)$ & $(0.393)$ \\
\hline \multirow[t]{2}{*}{ Constant } & $12.09 * * *$ & $12.08 * * *$ & $12.29 * * *$ & $9.057 * * *$ & $8.361 * * *$ & $19.43^{* * *}$ & $11.15^{* * *}$ & $15.41^{* * *}$ \\
\hline & $(0.276)$ & $(0.278)$ & $(0.881)$ & $(1.263)$ & $(1.078)$ & $(6.740)$ & $(0.937)$ & $(1.628)$ \\
\hline Observations & 251,256 & 251,256 & 251,256 & 251,256 & 234,843 & 234,843 & 175,845 & 175,845 \\
\hline $\mathrm{R}$-squared & 0.214 & 0.214 & & & & & & \\
\hline Country FE & YES & YES & YES & YES & YES & YES & YES & YES \\
\hline Year FE & YES & YES & YES & YES & YES & YES & YES & YES \\
\hline Country x Year & YES & YES & NO & NO & NO & NO & NO & NO \\
\hline Excluded instruments & & & $\begin{array}{c}\text { Proportional } \\
\text { area of } \\
\text { processed floor }\end{array}$ & $\begin{array}{l}\text { Proportional } \\
\text { area of } \\
\text { processed floor } \\
\text { \& its square }\end{array}$ & \multicolumn{2}{|c|}{ Religion dummies } & \multicolumn{2}{|c|}{ Religion \& ethnicity dummies } \\
\hline J statistic (Sargan-Hansen test) & & & Just-identified & Just-identified & 19.868 & 2.620 & 46.963 & 43.145 \\
\hline $\mathrm{P}$-value & & & & & 0.0002 & 0.2698 & 0.0000 & 0.0000 \\
\hline
\end{tabular}


Table 5: Results of OLS and IV regressions using categorical variables of education and wealth as SES indicators

\begin{tabular}{|c|c|c|c|c|}
\hline & (1) & (2) & (3) & (4) \\
\hline Dependent variable: female BMI & OLS & IV3 & OLS & IV3 \\
\hline \multicolumn{5}{|l|}{ Education (Ref: No education) } \\
\hline Primary education & $\begin{array}{c}1.242 * * * \\
(0.0416)\end{array}$ & $\begin{array}{c}1.678 \\
(1.139)\end{array}$ & & \\
\hline Secondary education & $\begin{array}{l}1.905 * * * \\
(0.0498)\end{array}$ & $\begin{array}{c}7.701 * * * \\
(1.648)\end{array}$ & & \\
\hline Higher education & $\begin{array}{c}2.386 * * * \\
(0.0770)\end{array}$ & $\begin{array}{c}-8.757 * * \\
(4.432)\end{array}$ & & \\
\hline \multicolumn{5}{|l|}{ Wealth index (Ref: Poorest) } \\
\hline Poorer & & & $\begin{array}{c}0.634 * * * \\
(0.0469)\end{array}$ & $\begin{array}{l}-1.360 \\
(3.370)\end{array}$ \\
\hline Middle & & & $\begin{array}{c}1.292 * * * \\
(0.0488)\end{array}$ & $\begin{array}{c}19.34 * * * \\
(5.644)\end{array}$ \\
\hline Richer & & & $\begin{array}{c}2.187 * * * \\
(0.0528)\end{array}$ & $\begin{array}{c}-3.873 \\
(3.892)\end{array}$ \\
\hline Richest & & & $\begin{array}{c}3.487 \\
(0.0618)\end{array}$ & $\begin{array}{c}5.530 * * * \\
(1.759)\end{array}$ \\
\hline Age & $\begin{array}{c}0.361^{* * *} \\
(0.0126)\end{array}$ & $\begin{array}{c}0.865^{* * * *} \\
(0.198)\end{array}$ & $\begin{array}{c}0.321 * * * \\
(0.0124)\end{array}$ & $\begin{array}{c}0.329 * * * \\
(0.0559)\end{array}$ \\
\hline Square of age & $\begin{array}{c}-0.00374 * * * \\
(0.000189)\end{array}$ & $\begin{array}{c}-0.0101 * * * \\
(0.00252)\end{array}$ & $\begin{array}{c}-0.00331 * * * \\
(0.000186)\end{array}$ & $\begin{array}{c}-0.00337 * * * \\
(0.000745)\end{array}$ \\
\hline Current marital status (Ref: Single) & $\begin{array}{c}0.772 * * * \\
(0.0379)\end{array}$ & $\begin{array}{c}0.630 * * * \\
(0.166)\end{array}$ & $\begin{array}{c}0.609 * * * \\
(0.0370)\end{array}$ & $\begin{array}{c}0.788 * * * \\
(0.111)\end{array}$ \\
\hline Number of children & $\begin{array}{c}-0.0745 * * * \\
(0.00871)\end{array}$ & $\begin{array}{c}-0.278 * * * \\
(0.106)\end{array}$ & $\begin{array}{c}-0.0643 * * * \\
(0.00849)\end{array}$ & $\begin{array}{c}-0.101 \\
(0.0617)\end{array}$ \\
\hline Smoking (Ref: No) & $\begin{array}{c}1.105^{* * * *} \\
(0.109)\end{array}$ & $\begin{array}{c}0.642 * * * \\
(0.183)\end{array}$ & $\begin{array}{c}0.977 * * * \\
(0.107)\end{array}$ & $\begin{array}{c}0.743 * * \\
(0.306)\end{array}$ \\
\hline Number of rooms & $\begin{array}{c}0.0701 * * * \\
(0.0102)\end{array}$ & $\begin{array}{c}0.144 * * * \\
(0.0445)\end{array}$ & $\begin{array}{c}0.00615 \\
(0.00994)\end{array}$ & $\begin{array}{c}-0.0642 * \\
(0.0342)\end{array}$ \\
\hline Currently working (Ref: No) & $\begin{array}{c}0.373 * * * \\
(0.0323)\end{array}$ & $\begin{array}{c}0.318 * * * \\
(0.122)\end{array}$ & $\begin{array}{c}0.367 * * * \\
(0.0321)\end{array}$ & $\begin{array}{c}0.280 * * * \\
(0.0893)\end{array}$ \\
\hline Living area (Ref: Urban) & $\begin{array}{c}-1.511 * * * \\
(0.0403)\end{array}$ & $\begin{array}{c}-1.815^{* * * *} \\
(0.306)\end{array}$ & $\begin{array}{c}-0.395 * * * \\
(0.0448)\end{array}$ & $\begin{array}{l}-1.949 * \\
(1.184)\end{array}$ \\
\hline Constant & $\begin{array}{c}12.62 * * * \\
(0.269)\end{array}$ & $\begin{array}{c}3.728 \\
(3.804)\end{array}$ & $\begin{array}{c}11.59 * * * \\
(0.269)\end{array}$ & $\begin{array}{c}14.33 * * * \\
(1.772)\end{array}$ \\
\hline Observations & 265,264 & 186,997 & 265,284 & 187,001 \\
\hline R-squared & 0.209 & & 0.228 & \\
\hline Country FE & YES & YES & YES & YES \\
\hline Year FE & YES & YES & YES & YES \\
\hline Country x Year & YES & NO & YES & NO \\
\hline Excluded instruments & & $\begin{array}{c}\text { Religion \& } \\
\text { ethnicity } \\
\text { dummies }\end{array}$ & & $\begin{array}{c}\text { Religion \& } \\
\text { ethnicity } \\
\text { dummies }\end{array}$ \\
\hline J statistic (Sargan-Hansen test) & & 7.939 & & 2.447 \\
\hline P-value & & 0.1596 & & 0.6541 \\
\hline
\end{tabular}

Note: $* * * \mathrm{p}<0.01, * * \mathrm{p}<0.05, * \mathrm{p}<0.1$. All data are weighted and clustering methods at the PSU level were applied. Robust standard errors are in parentheses. IV3 is instrumented by the combination of religion and ethnicity dummies.

Source: Authors' calculation using DHS data for SSA (1990-2019). 


\subsection{Validity of instruments}

Although each set of instruments demonstrated its strength and relevance as a predictor of female education and household wealth (as shown in Table S1 of Supplementary Materials), we cannot convincingly test the exogeneity requirement. Notwithstanding, the Hansen-Sargan test makes it possible to check for the absence of correlation between residuals and instruments (null hypothesis). As shown at the bottom of Tables 3, 4, and 5, the indications provided by this test regarding the exogeneity of IV2 and IV3 are not clear, which may cast doubt on the validity of both instruments. In Tables 3 and 4, this test leads to reject the null hypothesis (i.e., no correlation) when using a linear specification, but suggests the opposite when quadratic specification is used, at least for IV2. In Table 5, this test leads to the acceptation of the null hypothesis for IV3 when categorical specifications of SES are considered. For our preferred instrument (IV1), Eq.2 is exactly identified; hence we are not able to apply the Hansen-Sargan test. Despite the opacity regarding the exogeneity of instruments, even if our IV regressions are not perfect, the findings are consistent and provide a better understanding of the relationship between SES indicators and female BMI in SSA.

\section{Discussion}

The aim of the present study was to update our understanding of the relationship between SES and BMI in SSA, here focused on women aged 18-49. Pooling data covering almost 30 years (from 1990 to 2019) from 36 SSA countries, we combined OLS regressions and IV corrections to control for observed characteristics and potential endogeneity bias. Our results emphasize a change in the relationship between SES and female BMI during the process of economic development. Specifically in SSA, we found that the burden of overweight or obesity is tending to shift from the most educated women to women with intermediate levels of education. Likewise, we observed a similar shift in the female BMI distribution with respect to household wealth indicators. This social shift is consistent with the nutrition transition theory 
(Popkin, 1993; Monteiro et al., 2004), in which the burden of obesity moves from the most privileged individuals to the least privileged individuals, but first transits through intermediate social groups, in parallel with economic development and the rise of obesity.

Another contribution of this study is that it dates the social shift of the obesity burden in SSA: further exploration of heterogeneous effects showed that the shift began in the end of the 1990s. These explorations also revealed that the U-inverted relationship between SES and female BMI is more robust among lower middle income countries in SSA, compared to other groups of countries (low income and upper middle income). This result is also innovative because it quantitatively illustrates the ongoing nutrition transition in lower middle income countries, a set of countries rarely analyzed from this perspective.

It is not really surprising that the quadratic specifications of SES are less significant for low income countries, since these countries are presumably at a less advanced stage of their nutrition transition (undernutrition remains relatively high and obesity relatively low). Hence, the social shift has probably not yet happened in low income countries (at least not to a significant extent) and the SES-BMI relationship is likely to be still positive. By contrast, the results found for upper middle income countries are more surprising, since the countries in this group are likely to be at a more advanced stage of the nutrition transition (high rates of obesity). Moreover, these results are not in agreement with those of previous studies that showed nonlinear trends in the social distribution of BMI among upper middle income countries worldwide, including South Africa (Bonnefond \& Clément, 2014; Clément, 2017; Levasseur, 2015; Strauss \& Thomas, 2007; Tafreschi, 2015; Wariri et al., 2021). However, two arguments can be put forward to explain why the U-inverted link between SES and female BMI is not really robust in the subsample of upper middle income countries in SSA. First, in addition to a limited number of observations, this subsample is extremely heterogeneous: it only includes three countries (South Africa, Namibia, and Gabon) with different sample sizes, different levels of average education 
and wealth, and different stages of the nutrition transition (see Table 1). Moreover, as shown in Table 2, the gap in the average BMI across SES categories is small among upper middle income countries (e.g., only $+1.5 \mathrm{~kg} / \mathrm{m}^{2}$ between no education and high education). Hence, the opportunity to observe a robust nonlinear trend in this subsample is relatively low without the use of more detailed measurement of SES such as household income.

Finally, our study includes some limitations that could be topics of future research. First, since the study conjointly analyzes women from 36 SSA countries, regional specificities are not explored. Specific studies on local areas or countries should be conducted to provide comparative insights, namely regarding potential heterogeneity in weight perception. Another limitation is that this study relies on the data restrictions imposed by the use of DHS data. Not only were we obliged to omit the income dimension of SES, but also to exclude male subjects from our analysis because too few DHS include anthropometric data for men. Notwithstanding these limitations, our results have important implications for public policy, but also for development programs funded by international agencies that often focus on women's health. Specifically, the social shift described by the results reveals the urgent need to adapt health programs and anti-obesity actions in a context where both hunger and overweight coexist and affect specific social groups in SSA countries differently. Furthermore, the increasing vulnerability of the emerging African middle in obesity risks (CFAO et al., 2016; May, 2018; Tschirley et al., 2015) may call for a higher regulation of the global food industry to reduce access to affordable high-fat high-sugar food and beverage; although such affordable products potentially reduce food insecurity related to hunger and underweight in the poorest regions of SSA where these issues highly persist (Boysen et al., 2019). 


\section{REFERENCES}

Agyemang, C., Boatemaa, S., Frempong, G. A., \& de-Graft Aikins, A. (2015). Obesity in Sub-Saharan Africa. In R. S. Ahima (Ed.), Metabolic Syndrome (pp. 1-13). Springer International Publishing. https://doi.org/10.1007/978-3-319-12125-3_5-1

Ameye, H., \& Swinnen, J. (2019). Obesity, income and gender: The changing global relationship. Global Food Security, 23, 267-281. https://doi.org/10.1016/j.gfs.2019.09.003

Angrist, J. D., \& Pischke, J.-S. (2008). Mostly Harmless Econometrics: An Empiricist's Companion. Princeton University Press.

Barnes, M. G., Smith, T. G., \& Yoder, J. K. (2013). Effects of household composition and income security on body weight in working-age men. Obesity, 21(9), E483-E489. https://doi.org/10.1002/oby.20302

Benedict, R. K., Schmale, A., \& Namaste, S. (2018). Adolescent nutrition 2000-2017: DHS data on adolescents Age 15-19 (DHS Comparative Reports No. 47). Article DHS Comparative Reports No. 47. https://www.dhsprogram.com/publications/publication-cr47-comparativereports.cfm

Biritwum, R., Gyapong, J., \& Mensah, G. (2005). The Epidemiology of Obesity in Ghana. Ghana Medical Journal, 39(3), 82-85.

Bonnefond, C., \& Clément, M. (2014). Social class and body weight among Chinese urban adults: The role of the middle classes in the nutrition transition. Social Science \& Medicine, 112, 22-29. https://doi.org/10.1016/j.socscimed.2014.04.021

Boysen, O., Boysen-Urban, K., Bradford, H., \& Balié, J. (2019). Taxing highly processed foods: What could be the impacts on obesity and underweight in sub-Saharan Africa? World Development, 119, 55-67. https://doi.org/10.1016/j.worlddev.2019.03.006

Carroll, J. F., Chiapa, A. L., Rodriquez, M., Phelps, D. R., Cardarelli, K. M., Vishwanatha, J. K., Bae, S., \& Cardarelli, R. (2008). Visceral Fat, Waist Circumference, and BMI: Impact of Race/ethnicity. Obesity, 16(3), 600-607. https://doi.org/10.1038/oby.2007.92 
Cawley, J. (2015). An economy of scales: A selective review of obesity's economic causes, consequences, and solutions. Journal of Health Economics, 43, 244-268. https://doi.org/10.1016/j.jhealeco.2015.03.001

Cawley, J., Moran, J., \& Simon, K. (2010). The impact of income on the weight of elderly Americans. Health Economics, 19(8), 979-993. https://doi.org/10.1002/hec.1541

CFAO, BearingPoint, \& Ipsos. (2016). The middle classes in Africa: Realities and challenges (White Papers).

Clément, M. (2017). The income-body-size gradient among Chinese urban adults: A semiparametric analysis. China Economic Review, 44, 253-270. https://doi.org/10.1016/j.chieco.2017.05.003

Cohen, E., Boetsch, G., Palstra, F. P., \& Pasquet, P. (2013a). Social valorisation of stoutness as a determinant of obesity in the context of nutritional transition in Cameroon: The Bamiléké case. Social Science \& Medicine, 96, 24-32. https://doi.org/10.1016/j.socscimed.2013.07.004

Cohen, E., Boetsch, G., Palstra, F. P., \& Pasquet, P. (2013b). Social valorisation of stoutness as a determinant of obesity in the context of nutritional transition in Cameroon: The Bamiléké case. Social Science \& Medicine, 96, 24-32. https://doi.org/10.1016/j.socscimed.2013.07.004

Currie, J. (2009). Healthy, Wealthy, and Wise: Socioeconomic Status, Poor Health in Childhood, and Human Capital Development. Journal of Economic Literature, 47(1), 87-122.

Daran, B., Levasseur, P., \& Clément, M. (2020). Updating the association between socioeconomic status and obesity in sub-Saharan Africa: a literature review.

Flegal, K. M. (2006). Commentary: The epidemic of obesity—what's in a name? International Journal of Epidemiology, 35(1), 72-74. https://doi.org/10.1093/ije/dyi260

Franck, R., \& Rainer, I. (2012). Does the Leader's Ethnicity Matter? Ethnic Favoritism, Education, and Health in Sub-Saharan Africa. American Political Science Review, 106(2), 294-325. https://doi.org/10.1017/S0003055412000172

Gebremedhin, S. (2015). Prevalence and differentials of overweight and obesity in preschool children in Sub-Saharan Africa. BMJ Open, 5(12). https://doi.org/10.1136/bmjopen-2015-009005 
Hajek, P., Myers, K., Dhanji, A.-R., West, O., \& McRobbie, H. (2012). Weight change during and after Ramadan fasting. Journal of Public Health, 34(3), 377-381. https://doi.org/10.1093/pubmed/fdr087

Heaton, T. B. (2013). Religion and socioeconomic status in developing nations: A comparative approach. Social Compass, 60(1), 97-114. https://doi.org/10.1177/0037768612471772

Iyoke, C. A., Ugwu, G. O., Ezugwu, F. O., Lawani, O. L., \& Onyebuchi, A. K. (2013). Retrospective cohort study of the effects of obesity in early pregnancy on maternal weight gain and obstetric outcomes in an obstetric population in Africa. International Journal of Women's Health, 5, 501-507. https://doi.org/10.2147/IJWH.S49909

Jones-Smith, J. C., Gordon-Larsen, P., Siddiqi, A., \& Popkin, B. M. (2012). Is the burden of overweight shifting to the poor across the globe? Time trends among women in 39 low- and middle-income countries (1991-2008). International Journal of Obesity (2005), 36(8), 1114 1120. https://doi.org/10.1038/ijo.2011.179

Kim, D., \& Leigh, J. P. (2010). Estimating the Effects of Wages on Obesity. Journal of Occupational and Environmental Medicine, 52(5), 495-500. https://doi.org/10.1097/JOM.0b013e3181dbc867

Kpelitse, K.-A., Devlin, R., \& Sarma, S. (2014). The Effect of Income on Obesity among Canadian Adults. Undefined. /paper/The-Effect-of-Income-on-Obesity-among-Canadian-KpelitseDevlin/d0a5d5c70f907b827d9e6ecd16d6d70e15ee8ccc

Krieger, N., Williams, D. R., \& Moss, N. E. (1997). Measuring Social Class in US Public Health Research: Concepts, Methodologies, and Guidelines. Annual Review of Public Health, 18(1), 341-378. https://doi.org/10.1146/annurev.publhealth.18.1.341

Levasseur, P. (2015). Causal effects of socioeconomic status on central adiposity risks: Evidence using panel data from urban Mexico. Social Science \& Medicine, 136-137, 165-174. https://doi.org/10.1016/j.socscimed.2015.05.018

Levasseur, P. (2019). Can social programs break the vicious cycle between poverty and obesity? Evidence from urban Mexico. World Development, 113, 143-156. https://doi.org/10.1016/j.worlddev.2018.09.003 
May, J. (2018). Keystones affecting sub-Saharan Africa's prospects for achieving food security through balanced diets. Food Research International, 104, 4-13. https://doi.org/10.1016/j.foodres.2017.06.062

McLaren, L. (2007). Socioeconomic Status and Obesity. Epidemiologic Reviews, 29(1), 29-48. https://doi.org/10.1093/epirev/mxm001

Merwe, M.-T. V. D., \& Pepper, M. S. (2006). Obesity in South Africa. Obesity Reviews, 7(4), 315322. https://doi.org/10.1111/j.1467-789X.2006.00237.x

Monteiro, C. A., Conde, W. L., Lu, B., \& Popkin, B. M. (2004). Obesity and inequities in health in the developing world. International Journal of Obesity and Related Metabolic Disorders: Journal of the International Association for the Study of Obesity, 28(9), 1181-1186. https://doi.org/10.1038/sj.ijo.0802716

Monteiro, C. A., Moura, E. C., Conde, W. L., \& Popkin, B. M. (2004). Socioeconomic status and obesity in adult populations of developing countries: a review. Bulletin of the World Health Organization, 82(12), 940-946. https://doi.org//S0042-96862004001200011

NCD Risk Factor Collaboration (NCD-RisC). (2016). Trends in adult body-mass index in 200 countries from 1975 to 2014: a pooled analysis of 1698 population-based measurement studies with 19.2 million participants. The Lancet, 387(10026), 1377-1396. https://doi.org/10.1016/S0140-6736(16)30054-X

Ngaruko, F., \& Nkurunziza, J. D. (2000). An economic interpretation of conflict in Burundi. Journal of African Economies, 9(3), 370-409. https://doi.org/10.1093/jae/9.3.370

Onubi, O. J., Marais, D., Aucott, L., Okonofua, F., \& Poobalan, A. S. (2016). Maternal obesity in Africa: a systematic review and meta-analysis. Journal of Public Health (Oxford, England), 38(3), e218-e231. https://doi.org/10.1093/pubmed/fdv138

Pellow, D. (2015). Multiple Modernities. Home Cultures, 12(1), 55-81. https://doi.org/10.2752/175174215X14171915160290

Pieroni, L., \& Salmasi, L. (2010). Body weight and socio-economic determinants: Quantile estimations from the British Household Panel Survey (Working Paper No. 2010-41). ISER Working Paper Series. https://www.econstor.eu/handle/10419/65941 
Popkin, B. M. (1993). Nutritional Patterns and Transitions. Population and Development Review, 19(1), 138-157. JSTOR. https://doi.org/10.2307/2938388

Renzaho, A. M. N. (2004). Fat, rich and beautiful: changing socio-cultural paradigms associated with obesity risk, nutritional status and refugee children from sub-Saharan Africa. Health \& Place, 10(1), 105-113. https://doi.org/10.1016/S1353-8292(03)00051-0

Schmeiser, M. D. (2009). Expanding wallets and waistlines: the impact of family income on the BMI of women and men eligible for the Earned Income Tax Credit. Health Economics, 18(11), 1277-1294. https://doi.org/10.1002/hec.1430

Shabaya *, J., \& Konadu-Agyemang, K. (2004). Unequal access, unequal participation: some spatial and socio-economic dimensions of the gender gap in education in Africa with special reference to Ghana, Zimbabwe and Kenya. Compare: A Journal of Comparative and International Education, 34(4), 395-424. https://doi.org/10.1080/0305792042000294805

Shekar, M., \& Popkin, B. (Eds.). (2020). Obesity: Health and Economic Consequences of an Impending Global Challenge. The World Bank. https://doi.org/10.1596/978-1-4648-1491-4

Sobal, J., \& Stunkard, A. J. (1989). Socioeconomic status and obesity: a review of the literature. Psychological Bulletin, 105(2), 260-275. https://doi.org/10.1037/0033-2909.105.2.260

Strauss, J., \& Thomas, D. (2007). Chapter 54 Health over the Life Course. In Handbook of Development Economics (Vol. 4, pp. 3375-3474). Elsevier. https://doi.org/10.1016/S15734471(07)04054-5

Stringhini, S., Viswanathan, B., Gédéon, J., Paccaud, F., \& Bovet, P. (2013). The social transition of risk factors for cardiovascular disease in the African region: Evidence from three crosssectional surveys in the Seychelles. International Journal of Cardiology, 168(2), 1201-1206. https://doi.org/10.1016/j.ijcard.2012.11.064

Tafreschi, D. (2015). The income body weight gradients in the developing economy of China. Economics \& Human Biology, 16, 115-134. https://doi.org/10.1016/j.ehb.2014.02.001

The World Bank. (2019). World Bank Country and Lending Groups. World Bank Data Help Desk. https://datahelpdesk.worldbank.org/knowledgebase/articles/906519-world-bank-country-andlending-groups 
Tschirley, D., Reardon, T., Dolislager, M., \& Snyder, J. (2015). The Rise of a Middle Class in East and Southern Africa: Implications for Food System Transformation. Journal of International Development, 27(5), 628-646. https://doi.org/10.1002/jid.3107

Tusting, L. S., Ippolito, M. M., Willey, B. A., Kleinschmidt, I., Dorsey, G., Gosling, R. D., \& Lindsay, S. W. (2015). The evidence for improving housing to reduce malaria: a systematic review and meta-analysis. Malaria Journal, 14(1), 209. https://doi.org/10.1186/s12936-015-0724-1

Ugwuja, E. I., Akubugwo, E. I., Obidoa, O., \& Ibiam, A. U. (2010). Maternal BMI during Pregnancy: Effect on trace elements Status and Pregnancy Outcomes. International Journal of Health Research, 3(2), 71-78. https://doi.org/10.4314/ijhr.v3i2.70270

Villamor, E., Msamanga, G., Urassa, W., Petraro, P., Spiegelman, D., Hunter, D. J., \& Fawzi, W. W. (2006). Trends in obesity, underweight, and wasting among women attending prenatal clinics in urban Tanzania, 1995-2004. The American Journal of Clinical Nutrition, 83(6), 1387-1394. https://doi.org/10.1093/ajcn/83.6.1387

Wariri, O., Alhassan, J. A. K., Mark, G., Adesiyan, O., \& Hanson, L. (2021). Trends in obesity by socioeconomic status among non-pregnant women aged 15-49 y: a cross-sectional, multidimensional equity analysis of demographic and health surveys in 11 sub-Saharan Africa countries, 1994-2015. International Health, 13(5), 436-445.

https://doi.org/10.1093/inthealth/ihaa093

World Health Organization. (2014). Global status report on noncommunicable diseases 2014: attaining the nine global noncommunicable diseases targets; a shared responsibility. World Health Organization.

Yiga, P., Seghers, J., Ogwok, P., \& Matthys, C. (2020). Determinants of dietary and physical activity behaviours among women of reproductive age in urban sub-Saharan Africa: a systematic review. British Journal of Nutrition, 124(8), 761-772. https://doi.org/10.1017/S0007114520001828 


\section{END NOTES}

${ }^{1}$ Underweight, overweight and obesity statuses are defined using the body mass index (BMI), which is calculated by dividing weight $(\mathrm{kg})$ by squared height $\left(\mathrm{m}^{2}\right)$. The BMI cut-offs defined by the WHO to define underweight, overweight and obesity are respectively $18.5 \mathrm{~kg} / \mathrm{m}^{2}, 25 \mathrm{~kg} / \mathrm{m}^{2}$ and $30 \mathrm{~kg} / \mathrm{m}^{2}$. Hence, an individual is defined as underweight if his/her BMI is lower than 18.5, as normal weight if his/her BMI is comprised between 18.5 and 25 , as overweight if his/her BMI is higher than 25, and as obese if his/her BMI is higher than 30 .

2 The gender gap in obesity prevalence appears to be much higher for developing countries than rich countries, (Ameye \& Swinnen, 2019).

${ }^{3}$ The nutrition transition theory assumes a social shift of the obesity burden along with the process of economic development from the most privileged individuals to the least privileged individuals (Monteiro, Conde, et al., 2004; Monteiro, Moura, et al., 2004). During a country’s economic development, the lower social classes benefit from higher incomes and consume more goods associated with weight gain such as high-fat dense-calorie food, sweet drinks and other goods such as a TV. However, given the persistence of high-income inequality in developing countries, the improvement of incomes first occurs among middle social groups, the poorest being still associated with physical work and many deprivations including food deprivations. In contrast, individuals in the highest social groups would tend to adjust their diets and physical activity in order to invest in their future health. It is why the literature observes an overrepresentation of overweight and obesity among middle class in middle income countries.

${ }^{4}$ The DHS sampling approach works in two stages. In the first stage, the primary sampling units (PSUs) are selected with probability proportional to size (PPS) within each stratum (usually census enumeration areas - EAS). In the second stage, a fixed number of households is selected from a complete household census by equal probability systematic sampling in the selected cluster. As a matter of fact, because the overall probability of selection of each household differs, the data must be weighted.

${ }^{5}$ We re-weight the sample using the number of women aged 15 to 49 because no population data are available regarding the number of women aged 18 to 49 for each country and wave.

${ }^{6}$ Eq. 2 does not include interactions between country and time fixed effects terms to simplify measurements. We obviously tested Eq.2 including these interactions but the results were similar and the power of prediction of the model (adjusted R-square) was unchanged. 
${ }^{7}$ As shown in Levasseur (2015), and to some extent in Iyoke et al. (2013), aging has a U-inverted relationship with female BMI, and marriage, smoking and urban lifestyles tend to increase female BMI. Likewise, in line with Clément (2017) and Villamor et al. (2006), female employment is positively related to BMI. Further, the number of children is generally negatively correlated with female BMI, except for some IV models. This ambiguity has several possible explanations. While multiparous mothers have a higher risk of being overweight and obese in SSA (Onubi et al., 2016), Gebremedhin (2015) explains that household size has potential negative externalities on the nutrition of all family members in deprived settings, an additional child reducing the marginal food intake of all members of the household. In relation to our results, one can assume that mothers are the most likely to reduce their own food intakes compared to other household members, skipping lunch or dinner for example. Finally, housing size appears to be correlated with female BMI in OLS estimates, but the sign of this correlation is highly sensitive to the model specification depending on the indicator of SES used (positive in Table 3 but negative in Table 4). This ambiguity in the correlation of housing size with female BMI in SSA is also emphasized in the literature (Ugwuja et al., 2010; Onubi et al., 2016).

${ }^{8}$ Three sets of instruments are tested: (IV1) percentage area of processed floors in housing (and its square when quadratic specifications are considered); (IV2) religious affiliation dummies; (IV3) combination of religious affiliation and ethnic-rank dummies. 